\title{
E-cigarettes and smoking cessation: a critique of a New England Journal Medicine-commissioned case study
}

\author{
Riccardo Polosa ${ }^{1,2,3} \cdot$ Pasquale Caponnetto ${ }^{1,2}$
}

Received: 10 July 2016/Accepted: 9 September 2016/Published online: 24 September 2016

(C) The Author(s) 2016. This article is published with open access at Springerlink.com

Keywords Smoking cessation $\cdot$ Smoking reduction .

Electronic cigarette $\cdot$ Tobacco harm reduction

A recent article in the NEJM [1] illustrates the case vignette of a male smoker being seen at a routine health checkup that prompted him to enquiry about quitting using e-cigarettes.

He is 29 years old, but with a significant medical history of obesity (current BMI $=31$ ), hypertension (current BP is $128 / 76 \mathrm{mmHg}$ on chlorthalidone $25 \mathrm{mg}$ daily) and childhood seizures. The rest of the physical examination and the review of his systems were unremarkable.

The patient started smoking when he was 15 years old, and he has been smoking up to 1.5 packs per day for the past 6 years. He has reduced or stopped smoking several times in the past using various nicotine replacement therapies (NRTs) or by quitting "cold turkey". On each occasion, he was able to sustain his efforts for up to 3 weeks before relapsing into his previous smoking habits.

There follows a discussion about the danger of smoking and potentially useful smoking cessation aids. The patient has friends who have stopped smoking cigarettes by switching to regular use of e-cigarettes. He is now

Riccardo Polosa

polosa@unict.it

1 Centro Prevenzione e Cura del Tabagismo, Azienda Ospedaliero Universitaria "Policlinico-V. Emanuele", Catania, Italy

2 Dipartimento di Medicina Clinica e Sperimentale, Università di Catania, Catania, Italy

3 UOC di Medicina Interna e d'Urgenza, Azienda Ospedaliero Universitaria "Policlinico-V. Emanuele", Catania, Italy interested in giving up smoking by trying e-cigarettes, and asks for an opinion.

The Editorial staff at the NEJM invites two experts to provide their personal recommendations.

Expert no. 1 is Christopher Bullen, a professor of Public Health at the Faculty of Medical and Health Sciences of the University of Auckland. His research interests focus primarily on tobacco control and innovative smoking cessation interventions research, including e-cigarettes. He also has wider interests in research on population health education, and heart disease prevention and treatment. He directs the National Institute for Health Innovation (NIHI).

$\mathrm{He}$ recommends trying e-cigarettes for smoking cessation because he thinks that the patient has limited pharmacologic treatment options (contraindications for bupropion and varenicline prescription due to his history of seizures; inability to abstain from smoking on several occasions despite being on NRT).

Expert no. 2, is Stanton Glantz, a professor of Medicine in the Division of Cardiology, and American Legacy Foundation Distinguished Professor of Tobacco Control. $\mathrm{He}$ conducts research on a wide range of topics ranging from the health effects of second hand smoke (with particular emphasis on the cardiovascular system) to the efficacy of different tobacco control policies. His work has recently expanded to include e-cigarettes. He directs the Center for Tobacco Control Research and Education at the University of California, San Francisco (UCSF) School of Medicine.

He tries to convince the patient that he should reconsider his interest in giving up smoking by trying e-cigarettes by applying a motivational approach based on the results of a-flawed-meta-analysis showing that these products are not proven to assist smoking cessation [2]. The metaanalysis took studies that contained no useful information 
on whether vaping helps smokers to quit, and misreported them as if they were showing that vaping undermines quitting. These were primary studies that compared smokers who tried vaping, but continued to smoke with smokers who did not try vaping. Smokers who tried vaping and successfully stopped smoking were excluded, so treatment efficacy was evaluated only on treatment failures. In relation to the patient's case, he does not provide any solution besides suggesting to stop using conventional cigarettes (easier said than done).

We (Dr. R. Polosa and Dr. P. Caponnetto) run one of Italy's busiest smoking cessation centers, and have helped thousands of smokers who successfully quit with several methods including e-cigarettes. We were the first in the world to publish a smoking cessation study, a RCT, and the longest clinical follow-up with e-cigarettes. According to a recent bibliometric analysis [3], we have been ranked as the top most prolific authors who published in the field of e-cigarettes.

We were pleased to see featured this case study of a 29-year-old man interested in giving up smoking by switching to e-cigarettes in the NEJM, and we would like to offer our personal opinion, bringing into the debate the combined experience of an experienced internist ( $R$. Polosa) with that of a clinical psychologist who is in charge of multimodal smoking cessation programs (P. Caponnetto).

The case study presented is more challenging than actually appears for several reasons.

The patient is relatively young, and quit rates in young adults are known to be very low as proven by his history of frequent relapses. There is no evidence demonstrating the efficacy of FDA-approved smoking cessation drugs for young adults. Thus, FDA-approved smoking cessation drugs cannot be recommended for young adults.

The patient's history indicates that he is at high risk of relapse. While international guidelines place great emphasis on relapse prevention, very little can be done to manage smokers with a history of frequent relapses [4]. If the patient is willing, increasing the intensity and frequency of cessation counseling or adding another first line medication may increase success rates. Nevertheless, as mentioned earlier, there is no evidence to support the recommendation of smoking cessation medications for young adults who smoke.

The patient is already overweight, and is being treated for hypertension. Stopping smoking is known to lead to weight gain in four out of five quitters. Hence, it is important to consider that he-if successful-will have to deal with the burden of post-cessation weight gain with its important negative health consequences, particularly in consideration of the fact that obesity and hypertension are well known risk factors for cardiovascular disease.
While there is no doubt that stopping smoking will result in considerable health improvements, the patient requires an alternative approach. An additional option is to encourage him to switch to a much cleaner source of nicotine. Given that his personal preference is to try e-cigarettes to quit smoking, his choice should be respected, and the health care provider should offer a balanced overview of their risk/benefit ratio [5].

More specifically, relevant to this patient's clinical history, it is worth noticing that (1) e-cigarettes have helped abstaining from conventional cigarette young adults as well as older ones [6]; (2) e-cigarettes have been shown to reduce post-cessation weight gain in quitters [7]; (3) smokers with elevated blood pressure who quit by switching to e-cigarettes may lower their BP in the longterm [8].

Physicians should advise smokers about the most effective ways to quickly reduce their risk. While smoking cessation may be the most desirable final outcome from a health point of view, it may be the wrong goal if it leads to failure or relapse. Physicians should consider all the pathways available to a smoking patient, and select the ones that give the greatest probability of eliminating exposure to tobacco smoking, including e-cigarettes. There is now increasing evidence that-for many smokers-the best outcome may be a long-term switch to vaping, tolerating the small residual risk in return for a higher likelihood of success.

\section{Compliance with ethical standards}

Conflict of interest RP has received lecture fees and research funding from Pfizer and GlaxoSmithKline, manufacturers of stop smoking medications. He has also served in the past as a consultant for Pfizer and Arbi Group Srl, an Italian distributor of e-Cigarettes. RP is currently a scientific advisor for LIAF, Lega Italiana Anti Fumo (Italian acronym for Italian Anti Smoking League). PC has no relevant conflict of interest to declare in relation to this work.

Statement of human and animal rights This article does not contain any study with human and animals performed by any of the authors.

Informed consent Informed consent is not applicable.

Open Access This article is distributed under the terms of the Creative Commons Attribution 4.0 International License (http://crea tivecommons.org/licenses/by/4.0/), which permits unrestricted use, distribution, and reproduction in any medium, provided you give appropriate credit to the original author(s) and the source, provide a link to the Creative Commons license, and indicate if changes were made.

\section{References}

1. Yeh JS, Bullen C, Ch B, Glantz SA (2016) Clinical decisions E-cigarettes and smoking cessation. N Engl J Med 374:2172-2174 
2. Hajek P, McRobbie H, Bullen C (2016) E-cigarettes and smoking cessation. Lancet Respir Med 4(6):e23. doi:10.1016/S22132600(16)30024-8 (Epub 2016 Apr PubMed)

3. Zyoud SH, Al-Jabi SW, Sweileh WM (2014) Worldwide research productivity in the field of electronic cigarette: a bibliometric analysis. BMC Public Health 14:667. doi:10.1186/1471-2458-14667

4. Caponnetto P, Keller E, Bruno CM et al (2013) Handling relapse in smoking cessation: strategies and recommendations. Intern Emerg Med 8(1):7-12

5. Farsalinos KE, Polosa R (2014) Safety evaluation and risk assessment of electronic cigarettes as tobacco cigarette substitutes: a systematic review. Ther Adv Drug Saf 5(2):67-86
6. Choi K, Forster J (2013) Characteristics associated with awareness, perceptions, and use of electronic nicotine delivery systems among young US Midwestern adults. Am J Public Health 103(3):556-561

7. Russo C, Cibella F, Caponnetto P et al (2016) Evaluation of post cessation weight gain in a 1-year randomized smoking cessation trial of electronic cigarettes. Sci Rep 6:18763. doi:10.1038/ srep 18763

8. Farsalinos K, Cibella F, Caponnetto P et al (2016) Effect of continuous smoking reduction and abstinence on blood pressure and heart rate in smokers switching to electronic cigarettes. Intern Emerg Med 11(1):85-94 